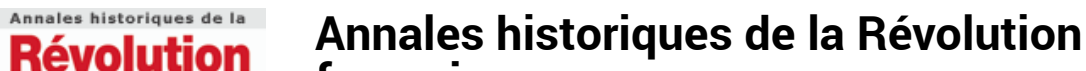

française française

370 | octobre-décembre 2012

Varia

\section{Alain COHEN, Le Comité des Inspecteurs de la salle. Une institution originale au service de la Convention nationale (1792-1795)}

Jean Bart

\section{OpenEdition}

\section{Journals}

Édition électronique

URL : https://journals.openedition.org/ahrf/12539

DOI : $10.4000 /$ ahrf. 12539

ISSN : 1952-403X

Éditeur :

Armand Colin, Société des études robespierristes

\section{Édition imprimée}

Date de publication : 1 décembre 2012

Pagination : 236-238

ISBN : 978-2-200-92762-2

ISSN : 0003-4436

\section{Référence électronique}

Jean Bart, "Alain COHEN, Le Comité des Inspecteurs de la salle. Une institution originale au service de la Convention nationale (1792-1795) », Annales historiques de la Révolution française [En ligne], 370 | octobre-décembre 2012, mis en ligne le 28 janvier 2013, consulté le 24 avril 2022. URL : http:// journals.openedition.org/ahrf/12539; DOI : https://doi.org/10.4000/ahrf.12539

Ce document a été généré automatiquement le 24 avril 2022.

Tous droits réservés 


\title{
Alain COHEN, Le Comité des Inspecteurs de la salle. Une institution originale au service de la Convention nationale (1792-1795)
}

\author{
Jean Bart
}

\section{RÉFÉRENCE}

Alain COHEN, Le Comité des Inspecteurs de la salle. Une institution originale au service de la Convention nationale (1792-1795), préface de Michel Biard, Paris, L'Harmattan, 2011, 223 p., ISBN : 978-2-296-55894-6, 22,50€.

1 Quiconque serait rebuté par le titre et renoncerait à lire ce livre commettrait une erreur. Opportunément, le sous-titre souligne l'intérêt d'étudier une institution jusqu'alors ignorée, ou presque, dont le rôle dépassait largement la simple gestion du lieu où siégeaient les représentants du peuple.

2 L'« ébauche » d'un tel organe date des débuts de la Révolution, lorsque l'Assemblée, devenue constituante et donc permanente, fut confrontée à des problèmes pratiques évidents et, surtout, à la nécessité politique de se dégager de l'emprise du ministre de la Maison du Roi à laquelle la réunion des trois ordres avait été soumise. L'installation de la Constituante aux Tuileries en l'automne 1789, après un court séjour à l'Archevêché, rendit ces exigences encore plus impératives. Aussi l'Assemblée désigna-t-elle en son sein, à partir d'octobre 1790, des commissaires - dont le docteur Guillotin, célèbre à un autre titre - et des inspecteurs, "inspecteurs du travail des commis », car le nombre des employés nécessaires au bon fonctionnement du pouvoir législatif est vite devenu important, et « inspecteurs des dépenses des bureaux des comités » qui, elles aussi, ont rapidement augmenté. Commissaires et inspecteurs accomplissaient déjà «des fonctions administratives et financières très larges correspondant à la gestion de la 
salle et du personnel administratif », mais ils ne constituaient pas un comité spécifique, et il en fut de même sous la Législative.

Cependant, dès les premiers jours de la Convention, est ouvert un registre contenant les procès-verbaux d'un groupe bientôt désigné sous le nom de Comité des Inspecteurs de la salle, des bureaux et de l'Imprimerie de la Convention. Cinq autres registres du même genre seront remplis jusqu'au début de l'an III, ce qui révèle l'intensité des réunions de ce comité. Ses membres appartiennent naturellement à la Convention et sont, en principe, désignés par elle, selon une rotation périodique. Ce furent d'ailleurs les Inspecteurs de la salle qui prirent en charge l'organisation du renouvellement de tous les autres comités. Toutefois, au gré des événements politiques, les principes suivis en la matière ne furent pas toujours respectés, notamment sous la pression du "grand comité de salut public». Toujours est-il qu'avec beaucoup de précision Alain Cohen dresse la liste de tous ceux qui, à un moment ou à un autre, ont été choisis comme inspecteurs. Dans l'ensemble, pas de personnalités marquantes, sauf peut-être AntoineFrançois Sergent, graveur de son état, qui, après avoir été élu au comité de surveillance de Paris, puis révoqué, fut aussi, une fois devenu conventionnel, membre de la Commission des monuments historiques, puis du Comité d'instruction publique ; il fut, parmi les Inspecteurs de la salle, l'un des rares montagnards; outre quelques girondins ayant échappé à la guillotine, la plupart d'entre eux appartenaient à la Plaïne. Ce qui explique sans doute en partie la longévité du comité.

4 Le titre qui lui a été donné montre la variété des missions qui lui sont confiées et qu'il mène à bien grâce à un personnel technique ou de service relativement nombreux, d'autant qu'au cours des mois, pour résoudre les difficultés politiques et économiques auxquelles devaient faire face les députés, les attributions des inspecteurs se sont multipliées, au point que ceux-ci apparaissent un peu comme les hommes à tout faire de la Convention. Il est peu de domaines qui leur échappent. De leurs tâches diverses, minutieusement analysées par l'auteur, retenons l'organisation matérielle des instances délibératives, ne serait-ce, par exemple, que pour trouver, en période de pénurie, les milliers de livres de cire nécessaires à l'éclairage de la salle! Il faut aussi aménager des lieux qui n'étaient pas faits pour cela, et embellir le jardin situé autour du Palais national, ce qui n'a pas manqué de soulever des conflits de compétence, entre autres avec les services du ministère de l'Intérieur. Les Inspecteurs de la salle sont en contact direct avec les entreprises ou corps de métiers intervenant sur les lieux, comme avec les fournisseurs. Ils assurent donc d'abord un contrôle technique, mais aussi, par voie de conséquence, un contrôle financier. D'une façon générale, le comité s'est toujours montré fort attentif au bon emploi des deniers publics; il apparaît comme l'«artisan d'une très judicieuse politique immobilière ». C'est avec le même souci qu'il encadre les frais de fonctionnement de l'Assemblée, cherchant à prôner, par exemple, des économies d'énergie, ou qu'il veille au marché des draps nécessaires à la confection des costumes des représentants du peuple. Tout naturellement, son inspection s'étend à l'utilisation des sommes allouées aux députés, et particulièrement aux représentants en mission.

Chargés de la gestion des lieux où s'exerce le pouvoir, les Inspecteurs de la salle sont responsables de la sécurité de ceux qui y vivent ou y travaillent ; ils assurent la police des abords et des tribunes dont l'accès est réglementé par eux. Ils doivent aussi éviter que les abords et les jardins soient envahis par les marchands ou les agioteurs. Il faut surtout protéger les représentants du peuple contre l'intrusion d'opposants violents. $\mathrm{Si}$, 
au début, l'exécution des ordres des inspecteurs est confiée à la gendarmerie et à la garde nationale, le comité lui-même crée, en juillet 1793, une compagnie militaire spéciale composée d'invalides, destinée en particulier à protéger les statues et objets d'art installés dans les jardins. Ce qui ne manqua pas de mécontenter les membres du Comité militaire. En fait, le Comité des Inspecteurs de la salle touchait volontiers à tout, provoquant maints conflits de compétence et plaintes de la part d'autres autorités, causés par des empiétements d'autant plus mal supportés que la situation politique était tendue.

Il en fut ainsi même dans l'exercice d'une des fonctions premières et permanentes du comité : la surveillance des travaux de l'imprimerie nationale, une entreprise au statut curieux, qui succède dès 1789 à l'Imprimerie royale du Louvre et à celle du Cabinet du roi de Versailles. Ce n'est pas une entreprise publique et elle ne jouit pas du monopole de l'impression des nouvelles officielles. Sa nature mixte préfigurerait les catégories du droit administratif moderne. En tout cas, sous la Convention, son importance stratégique est certaine. Aussi le Comité des inspecteurs de la salle veille-t-il attentivement à l'approvisionnement des presses, grâce à la réquisition de papiers et étoffes, de même qu'il cherche à éviter les arrêts de travail provoqués par les manifestations d'ouvriers revendicatifs, sans renoncer davantage, en ce domaine, à la réquisition. Fut ainsi toujours assurée la diffusion des textes officiels, dont les procès-verbaux des séances de l'assemblée. À certains moments, d'ailleurs, les Inspecteurs eurent à donner leur avis sur la publication de mémoires ou discours justifiant les idées émises par tel ou tel député, ou encore de pétitions. Ce qui n'alla pas sans heurts. Ainsi, en novembre 1793, certains inspecteurs de la salle protestèrent contre l'intervention du ministre Roland qui avait empêché la diffusion d'une réponse de Robespierre à Louvet, alors que le texte de ce dernier avait été tiré à 15000 exemplaires pour être diffusé largement. Prudemment, le Comité se retranchait d'ordinaire derrière l'avis de la Convention, ou plutôt des comités de gouvernement.

7 En définitive, le Comité des Inspecteurs de la salle semble avoir été un instrument malléable dont la souplesse lui a permis de s'accommoder «fort bien de l'évolution politique de la Convention nationale jusqu'à sa séparation le 4 brumaire an IV ». Il faut savoir gré à Alain Cohen de l'avoir sorti de l'ombre. 